УДК $550.36(474.2)$

Геннадий УРБАН*, Лев ЦЫБУЛЯ**, Владимир КОЗЕЛ*, Андрес ШМИДТ***

\title{
ГЕОТЕРМИЧЕСКАЯ ХАРАКТЕРИСТИКА СЕВЕРНОЙ ЧАСТИ БАЛТИЙСКОЙ СИНЕКЛИЗЫ
}

К настоящему времени геотермическими исследованиями практически охвачена вся площадь Балтийской синеклизы. Наиболее слабо изученной оставалась ее северная часть (территория Эстонии), которую некоторые геологи относят к южному склону Балтийского щита (Волколаков, 1977). По приведенным в печати данным о распределении температур (Юрима, 1984), а также по отдельным определениям теплового потока (Гордиенко и др., 1984; Урбан, Цыбуля, 1988; Урбан, 1989) отмечается тенденция к уменьшению теплового поля в центральных районах и увеличению его в сторону побережья.

При определении теплового потока не всегда получаются достоверные результаты. Из причин отметим следующие:

а) моноклинальное залегание пород осадочного чехла, в строении которого участвуют верхнепротерозойские, кембрийские, ордовикские, силурийские, девонские и четвертичные образования, требует проведения детальных теплофизических исследований всего комплекса горных пород;

б) сложные гидрогеологические условия, обусловленные наличием в осадочном чехле большого количества тектонических нарушений и зон трещиноватости, которые местами сильно закарстованы;

в) небольшое количество скважин, пробуренных в породах кристаллического фундамента.

Измерение температур в скважинах выполнялось Әстонской гидрогеологической партией и Институтом геохимии и геофизики АН БССР. В некоторых случаях наряду с производственными замерами проводились также контрольные наблюдения институтом (см. таблицу). Максимальные расхождения между значениями температур установлены в скв. Кехра $777-0,4{ }^{\circ} \mathrm{C}$. Теплофизические свойства осадочных горных пород изучались нестационарным зондовым методом на образцах с естественной влажностью и в воздушно-сухом состоянии. Теплопроводность пород кристаллического фундамента определялась на установке ИТ-3, работающей в стационарном режиме (Любимова и др., 1964). Всего замерено 292 образца, из них 45 образцов кристаллических пород. Наиболее детально охарактеризованы карбонатные породы ордовика. Тепловые свойства силурийских и девонских отложений получены на воздушносухих образцах, отобранных в скважинах Пярну, Вильянди и Выру. Недостаточно изучен теплофизический разрез кембрийских и вендских образований. Исследования зависимости теплопроводности пород от содержания влаги показывают (Урбан, 1991а), что минимальная погрешность

* Інстытут геахіміi і геафізікі Акадэміі навук Беларускай ССР (Институт геохимии и геофизики Академии наук Белорусской ССР). 220067 Мінск, вул. Жозінская, 7.

** Геологический институт Кольского филиала Академии наук СССР. 184200 Мурманская область, Апатиты, ул. Ферсмана, 14.

*** NSVL Geoloogiaministeerium Eesti Geoloogiauuringute Tootmiskoondis (Эстонское производственное объединение по геологоразведочным работам). 200001 Tallinn, Pikk tn. 67. Estonia. 
характерна для известняков - не более $20 \%$, максимальная для девонских песчаников и алевролитов - $60 \%$, а в отдельных случаях и больше. Поэтому расчет теплового потока, где использовалась теплопроводность терригенных отложений, осуществлялся с учетом полученных поправок.

При вычислении теплового потока было замечено, что в верхней части разреза, представленного терригенными и карбонатными породами, наблюдается пониженный геотермический градиент. Плотность потока в этой зоне, по отношению к нижним горизонтам, уменьшается почти вдвое. Это дает основание предположить о наличии здесь конвективного переноса тепла, который приводит к выравниванию температур. Чтобы учесть возмущения теплового поля, изменяющиеся в зависимости от местоположения и глубины скважины, использовалась схема гидрогеологического районирования изучаемой территории. В зависимости от геофильтрационных условий она подразделена в плане на области и округа, а по вертикали - и геогидродинамически на зоны и подзоны (Валлнер, 1980). Наиболее достоверные определения потока будут в той части разреза, которая меньше всего обводнена, - это т. н. водоупоры (лонтоваская свита и кристаллический фундамент), а также карбонатные породы нижнего и среднего ордовика, залегающие глубже 100 м от поверхности (Перенс, 1984).

В округе $\mathrm{IV}_{2}$ (см. таблицу и рис. 1), за исключением скважин Киримяэ 350 и Инка 969, имеющиеся данные измерения температур позволяют рассчитывать тепловой поток в горизонтах с минимальной скоростью фильтрации воды, т.е. в подзонах замедленного и медленного стока. Средний тепловой баланс для этого округа (разность между значениями потока в нижних безводных толщах, где перенос тепла осуществляется молекулярным путем, и в верхних обводненных) составляет 15 мВт/м². Оцененные потери тепла учитывались при расчетах плотности потоков в неглубоких скважинах Киримяэ и Инка, поэтому на схему нанесены исправленные значения. Аналогичным образом введены поправки для скважин Ристи 1121를 Арувалла 1001, Маарду 529, Тырма 8531. В некоторых случаях, когда данные измерений в водоупорных толщах отсутствуют, такой балансовый подход невозможен. Поэтому в округе $\mathrm{II}_{1}$ и частично в округах $\mathrm{II}_{2}$ и $\mathrm{II}_{3}$ не определено количество выносимого тепла для скважин Қынну, Лелле, Кеава, Тори-Иыэсуу и Эллавере. В юго-восточной части территории (округ $\mathrm{I}_{2}$ ) геотермическими исследованиями охвачена главным образом подзона быстрого стока. И только лишь скв. Выру достигает подзоны умеренного стока, где прослеживается намечающееся увеличение потока с глубиной.

Измерение температур повсеместно выполнено в относительно неглубоких скважинах, поэтому здесь возможны искажения теплового поля, вызванные влиянием палеоклимата. Вычисления поправки в соседних районах показывают (Гордиенко и др., 1984), что ее величина не превышает $0-5 \mathrm{mBT} / \mathrm{m}^{2}$.

Для более полной характеристики геотермического поля северной части Балтийской синеклизы и сравнительного анализа наряду с распределением теплового потока (рис. 2) рассматриваются особенности изменения геотемператур на глубине 200 м (рис. 1). Оба рисунка выполнены на основе тектонической схемы кристаллического фундамента (Кристаллический..., 1983). Если на изучаемой территории уровень теплового поля в 35 мВт/м² принять за преобладающий, то на его фоне выделяются две явно выраженные аномалии - отрицательная в районе скв. Лелле и положительная на северо-востоке территории (рис. 2). Аналогичную ситуацию можно видеть и на схеме распределения температур (рис. 1), при этом здесь отчетливо прослеживается ход изотерм, совпадающий с главными направлениями разломов кристаллического фундамента и платформенного чехла. Әто свидетельствует об 


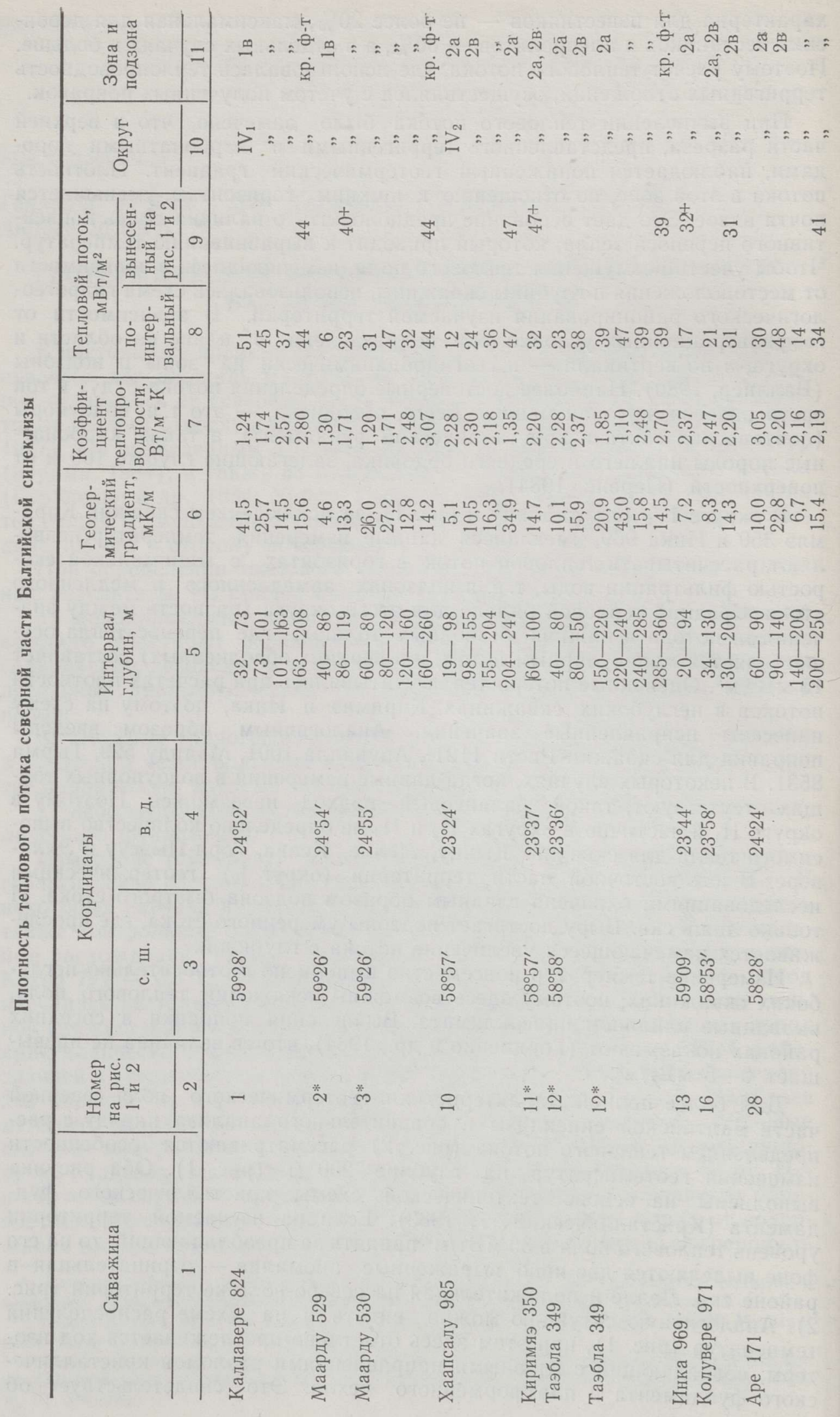




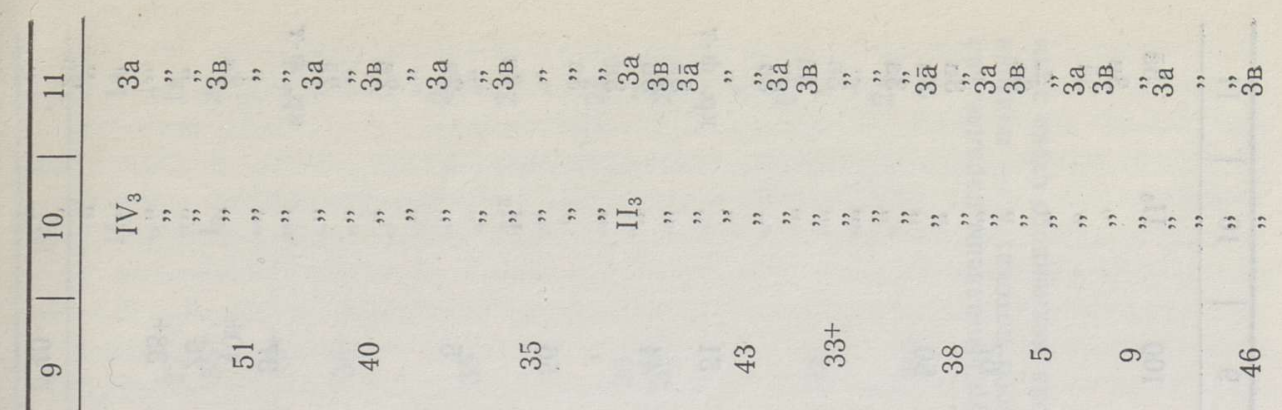

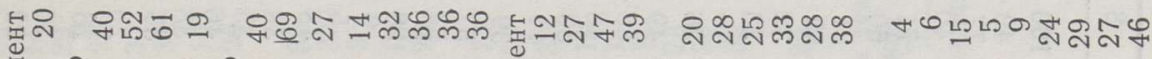

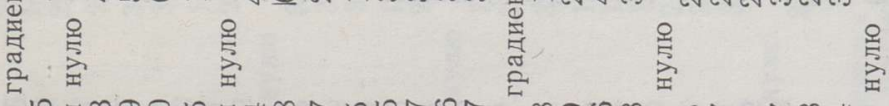

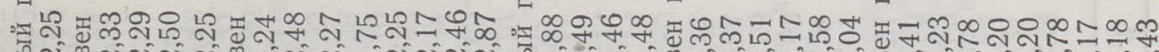

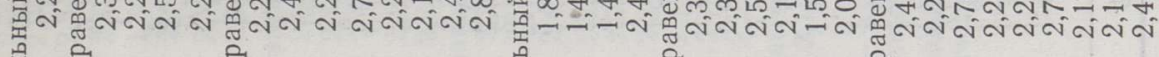
莺 F⿻肀

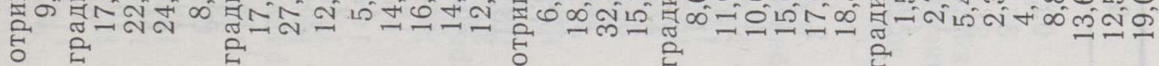

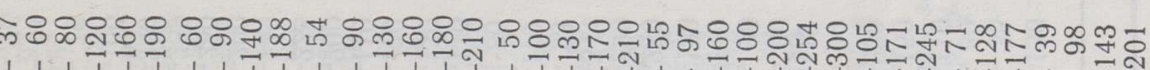

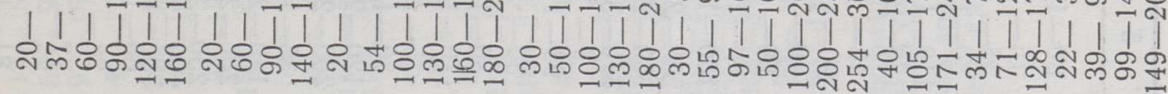

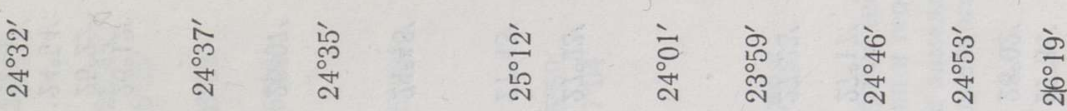

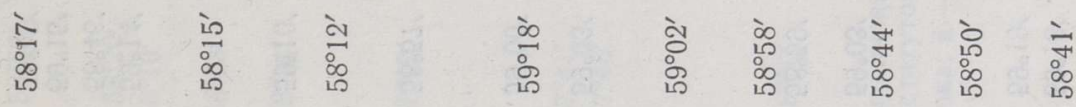




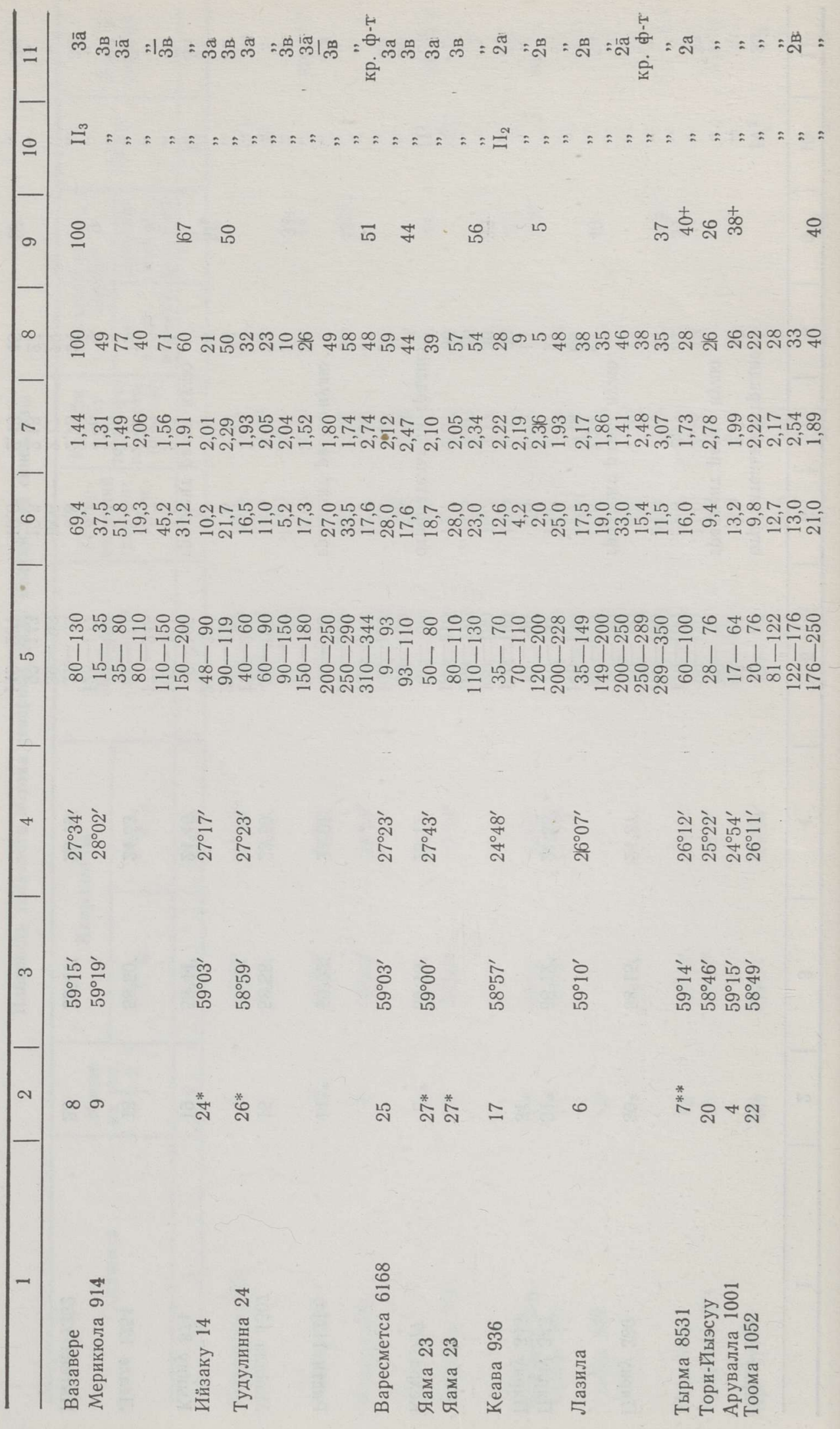


участии глубинных разломов в перераспределении источников тепла и их влиянии на условия теплопереноса в осадочных породах. Наличие отрицательной аномалии, по-видимому, обусловлено существующей зоной питания, причем поверхностные воды проникают по зонам трещиноватости здесь гораздо глубже, чем в соседних районах. Возможно, по достижении водоупорных толщ температуры резко возрастают и характер их распределения совершенно меняется. На юге-востоке ориентировка изотерм существенно расходится с положением разломной зоны и зависит, вероятно, от движения подземных вод в девонских отложениях. Аномальное увеличение температур на северо-востоке территории нельзя объяснить гидрогеологическими процессами, протекающими в верхней части разреза, так как имеющиеся измерения в водонепроницаемых горизонтах и кристаллическом фундаменте показывают, что тепло поступает из более глубоких слоев Земли.

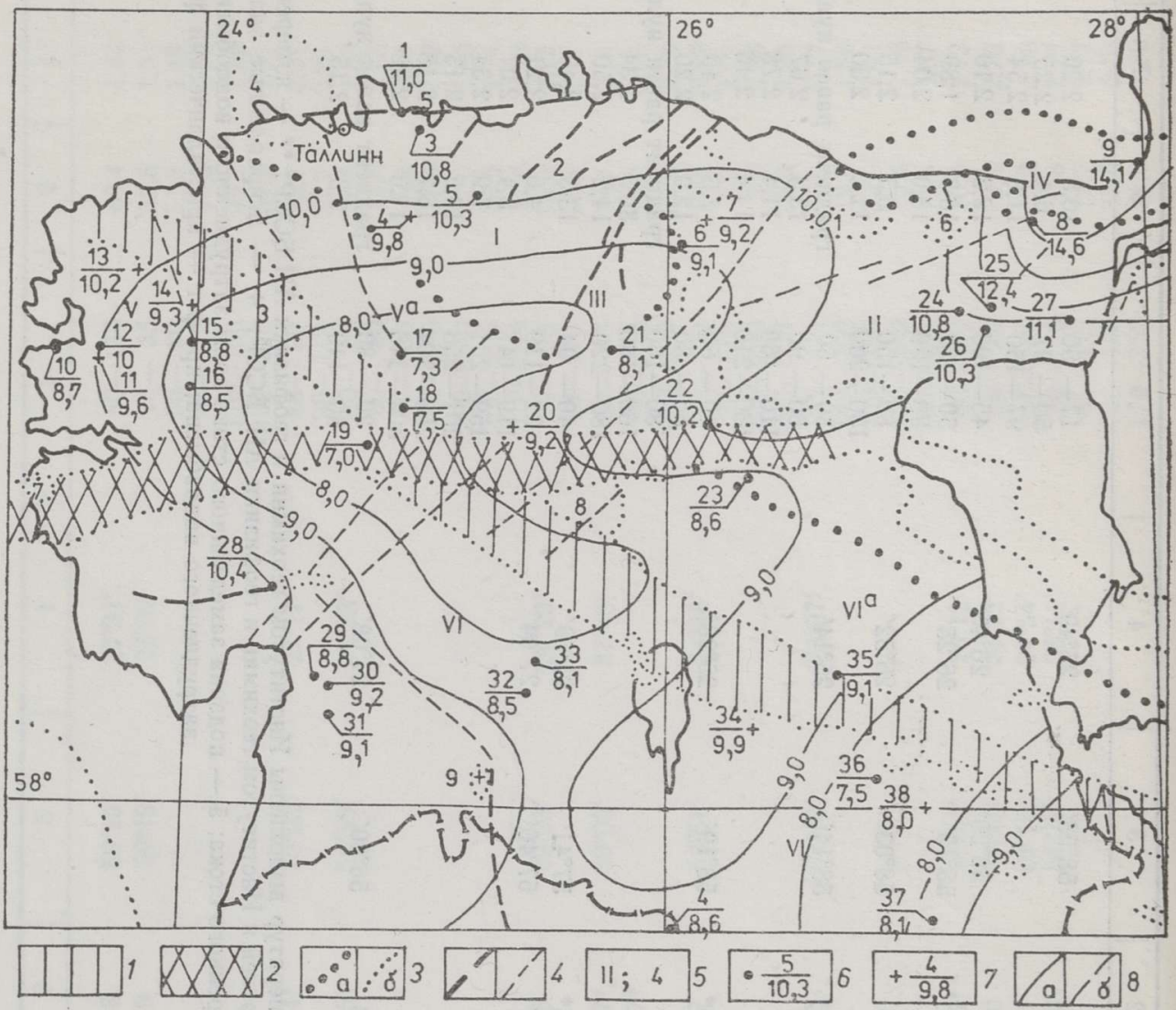

Рис. 1. Распределение температур на глубине 200 м. 1 - предполагаемая зона разлома и интенсивной гранитизации по юго-западному борту Палдиски-Псковской зоны; 2 субширотная зона разлома, дробления и милонитизации; 3 - геологические границы: а - складчатых областей, б - остальные; 4 - разломы: а - в фундаменте, б - платформенные разрывы, пересекающие осадочный чехол и кристаллический фундамент; 5 структурные элементы кристаллического фундамента: I Таллиннская зона, II Алутагузеская зона, III Тапаский блок, IV Йхвиская зона, V блоки архея Западной Әстонии, VI блоки архея Южной Эстонии $\left(\mathrm{V}^{\mathrm{a}}+\mathrm{VI}^{\mathrm{a}}-\right.$ Палдиски-Псковская зона); 1 - участок Сонда-Ульясте, 2 - Сигулаский массив габбро, 3-6 - массивы порфировидных гранитов: 3 - Мярьямааский, 4 - Найссаарский, 5 - Неэмеский, $6-$ Эредаский, $7-9-$ массивы гранодиоритов и кварцевых диоритов: 7 - Виртсу (Массо), 8 - Таадиквере, $9-$ Абья; 6 - местоположение скважин: в числителе - номер скважины, в знаменателе температура, ${ }^{\circ} \mathrm{C} ; 7$ - скважины с рассчитанными величинами температур; 8 - изотермы, ${ }^{\circ} \mathrm{C}:$ a - достоверные, б - предполагаемые. 
Ранее указывалось, что в поле тепловых потоков выделяются две аномалии. Природа отрицательной объяснена выше, здесь лишь заметим, что вычисленный в интервале $200-228$ м (скв. Кеава) поток 48 мВт/м² в какой-то мере служит подтверждением правильности рассуждений. В этой связи можно заключить, что северо-западная часть ЛатвийскоӘстонского массива, как и юго-юго-восточная, характеризуется в основном низкими значениями - в среднем 35 мВт/м². Небольшое увеличение потока на западе, в районе Хаапсалу, возможно, обусловлено прослеживающимся изменением состава архейских пород. Если массив сложен породами гранулитовой фации, которым соответствуют низкие величины теплогенерации (скв. Элва 1,0 мкВт/м³; Вильянди $2,4 \mathrm{mkBт} / \mathrm{m}^{3}$ ), то на западе - породами амфиболитовой фации, обладающими несколько повышенным содержанием радиоактивных элементов (Смыслов и др., 1979). Наблюдаемое увеличение потока в районе Пярну совпадает с «Пярнуским глубинным минимумом», выделенным по гравиметрическим данным (Кристаллический ..., 1983). Природу этого гравитационного минимума объясняют не выходящими на поверхность частями плутона кислых по составу пород, которые способны генерировать больше тепла, чем обрамляющие породы (Урбан, Цыбуля, 1988).

Тепловые потоки в Таллиннской зоне (сложенной амфиболитами, кварц-полевошпатовыми и глиноземистыми гнейсами) и в Неэмеском гранитном массиве несколько выше $(38-44$ м Вт/м²), чем в Латвийско-

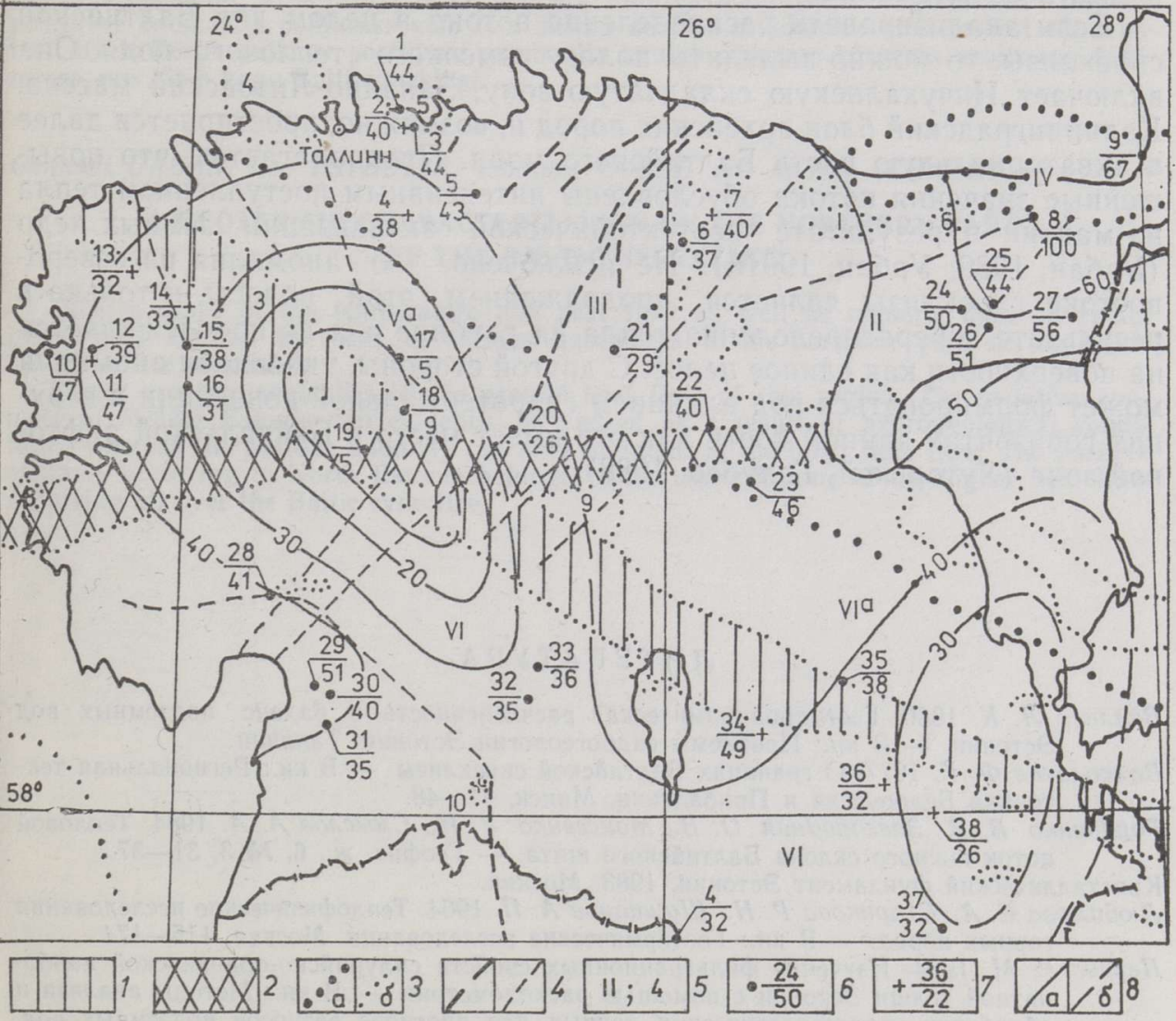

Рис. 2. Теплфвой поток тектонических структур кристаллического фундамента. Условные обозначения $1-5$ те же, что и на рис. $1.6-$ местоположение скважин: в числителе номер скважины, в знаменателе - плотность теплового потока, мВт/м²; 7 - скважины с исправленными значениями потока; 8 - изолинии теплового потока, мВт/м²: а - достоверные, б - предполагаемые. 
Эстонском массиве. По имеющимся отдельным измерениям концентрации радиоактивных элементов в порфировидных гранитах (скв. Маарду 505) проведена оценка теплогенерации, которая составляет $4,8-7,9 \mathrm{мкBт} / \mathrm{m}^{3}$. Следовательно, мощность гранитов Неэмеского массива невелика, в противном случае плотность потока была бы гораздо выше.

Большой интерес представляет положительная-аномалия тепловых потоков, охватывающая Алутагузескую и Йхвискую зоны и простирающаяся далее на северо-восток за пределы изучаемой территории. Величина потоков здесь колеблется в довольно широких пределах - от 44 до $100 \mathrm{mBT} / \mathrm{m}^{2}$, причем прослеживается закономерное увеличение его плотности с юга на север. Алутагузеская зона имеет двухэтажное строение: верхний сложен в основном глиноземистыми гнейсами, нижний архейскими гнейсами гранулитовой фации, которыми представлена кровля Йхвиского блока. Комплекс этих пород не охарактеризован данными по содержанию радиоактивных элементов, что создает трудности при интерпретации наблюдаемого потока. Однако следует учесть, что метаморфические породы Иыхвиской зоны аналогичны по составу породам гранулитовой фации Латвийско-Әстонского массива (Кристаллический ..., 1983), которые, как уже указывалось, не способны генерировать большое количество тепла. Тепловой поток здесь, наоборот, достигает максимального значения (скв. Вазавере), что дает основание полагать о наличии источника в недрах Земли, как для этого блока, так и для всей аномалии.

Если анализировать распределение потока в целом для Балтийской синеклизы, то можно выделить полосу высокого теплового поля. Она включает Инчукалнскую складчатую зону, Западно-Литовский массив, Калининградский блок архейских пород и, возможно, простирается далее в акваториальную часть Балтийского моря. Предполагается, что повышенные значения потока обусловлены интенсивным поступлением тепла из мантии в результате неотектонической активизации земных недр (Урбан, 1989; Урбан, 1991б). Не исключено, что аномалия на.северовостоке синеклизы является продолжением этой полосы, и только в результате перераспределения тепла на глубине она не прослеживается на поверхности как единое целое. С другой стороны, указанная аномалия может формироваться под влиянием гидротермальной конвекции в верхних горизонтах земной коры, как это имеет место в Байкальской рифтовой зоне (Хуторской, Голубев, 1988).

\section{ЛИТЕРАТУРА}

Валлнер Л. К. 1980. Геогидродинамическая расчлененность и баланс подземных вод Әстонии. - В кн.: Проблемы гидрогеологии Эстонии. Таллинн.

Волколаков Ф. К. 1977. О границах Балтийской синеклизы. - В кн.: Региональная тектоника Белоруссии и Прибалтики. Минск, $41-48$.

Гордиенко В. В., Завгородняя О. В., Моисеенко У. Н., Смыслов А. А. 1984. Тепловой поток южного склона Балтийского щита. - Геофиз. ж., 6, № 3, 31-37.

Кристаллический фундамент Эстонии. 1983. Москва.

Любимова Е. А., Старикова Р. Н., ШІушпанов А. П. 1964. Теплофизические исследования горных пород. - В кн.: Геотермические исследования. Москва, 115-174.

Перенс Р. М. 1984. Изучение фильтрационных свойств силурийско-ордовикской карбонатной толщи Эстонии с помощью расходометрии. - В кн.: Методы анализа и обработки гидрогеологических данных для прогноза ресурсов подземных вод.
Таллинн, $100-103$. Смыслов А. А.. Моисеенко У. И., Чадович Т. З. 1979. Тепловой режим и радиоактив-
ность Земли. Ленинград.

Урбан $Г$. 1989. Тепловой поток и радиогенная теплогенерация отдельных структур кристаллического фундамента Балтийской синеклизы. - Изв. АН ЭССР. Геол., 38,
№ 4, 155-160. 
Урбан Г. И. 1991а. Изменение коэффициента теплопроводности горных пород в зависимости от влажности (на примере девонских отложений Балтийской синеклизы). - В кн.: Сейсмические и геотермические исследования западной части СССР. Минск, (в печати).

урбан $Г$. 1991б. Новые определения теплового потока в пределах тепловой аномалии Балтийской си́неклизы. - Изв. АН Эстонии. Геол., 40, № 1, 24-25.

Урбан Г., Цыбуля Л. 1988. Тепловое поле Рижского плутона. - Изв. АН ЭССР. Геол., 37, № 2, 49-54.

хуторской М. Д., Голубев В. А. 1988. Геотермическая аномалия Прихубсугулья в системе Байкальской рифтовой зоны. - В кн.: Геотермические исследования на дне акваторий. Москва, $25-35$.

Юрима М.X. 1984. Применение методов геогидротермии для изучения водовмещающей толщи Эстонии. - В кн.: Методы анализа и обработки гидрогеологических данных для прогноза ресурсов подземных вод. Таллинн, 216-221.

Представил Д. Кальо

Поступила в редакцию 28/VIII 1990

\section{Gennadi URBAN, Lev TSOBULJA, Vladimir KOZEL, Andres SCHMIDT}

\section{BALTI SUNEKLIISI PÖJJAOSA GEOTERMILINE ISELOOMUSTUS}

On esitatud Balti sünekliisi põhjaosa maapõue temperatuuri ja soojusvoo skemaatilised kaardid ning aluskorra erinevate struktuuride kivimitest eralduva radiogeense soojushulga arvandmed. Vaadeldava ala maapõue soojusvoos eristub kaks anomaaliat. Negatiivset anomaaliat Kesk-Eestis saab seletada hüdrogeoloogilistest tingimustest lähtudes, positiivse anomaalia põhjuseks võib olla üksnes soojuse eraldumine suurematest sügavustest. Kirde-Eestis paiknev positiivne anomaalia kuulub ühtsesse körgema soojusvoo vöötmesse, mis läbib kogu Balti sünekliisi.

\section{Gennadi URBAN, Lev TSYBULIA, Vladimir COZEL and Andres SCHMIDT}

\section{A GEOTERMIC CHARACTERIZATION OF THE NORTHERN PART OF THE BALTIC SYNECLINE}

Sketch maps of the temperature and heat flow as well as numeric data on radiogenic heat emitted by rocks of various basements in the northern part of the Baltic synecline, are presented.

There are two anomalies in the ground heat flow of this region. The negative anomaly of Middle Estonia can evidently be viewed as a result of hydrogeological conditions, whereas the positive anomaly can only be found in the inner heat flow. The positive anomaly occurring in North Estonia belongs to the uniform zone of the higher heat flow occurring all over the Baltic synecline. 